\title{
Research Article \\ Effect of Heating Rate on the Dynamic Compressive Properties of Granite
}

\author{
Ronghua Shu, Tubing Yin $(\mathbb{D}$, and Xibing Li $\mathbb{D}$ \\ School of Resources and Safety Engineering, Central South University, Changsha 410083, China \\ Correspondence should be addressed to Tubing Yin; tubing_yin@mail.csu.edu.cn
}

Received 28 August 2018; Accepted 9 January 2019; Published 28 April 2019

Academic Editor: Ling-Li Zhou

Copyright () 2019 Ronghua Shu et al. This is an open access article distributed under the Creative Commons Attribution License, which permits unrestricted use, distribution, and reproduction in any medium, provided the original work is properly cited.

\begin{abstract}
Variation in the heating rate due to different geothermal gradients is a cause of much concern in underground rock engineering such as deep sea and underground tunnels, nuclear waste disposal, and deep mining. By using a split Hopkinson pressure bar (SHPB) and variable-speed heating furnace, the dynamic compressive properties of granite were obtained after treatments at different heating rates and temperatures; these properties mainly included the dynamic compressive strength, peak strain, and dynamic elastic modulus. The mechanism of heating rate action on the granite was simultaneously analyzed, and the macroscopic physical properties were discussed. The microscopic morphological features were obtained by scanning electron microscopy (SEM), and the crack propagation was determined by high-speed video camera. The experimental results show that the dynamic compressive strength and elastic modulus both show an obvious trend of a decrease with the increasing heating rate and temperature; the opposite phenomenon is observed for the peak strain. The relationships among the dynamic compressive properties and temperature could be described by the quadratic function. The ductility of granite is enhanced, and the number and size of cracks increase gradually when the heating rate and temperature increase. The microstructure of rock is weakened by the increased thermal stress, which finally affects the dynamic compressive properties of rock.
\end{abstract}

\section{Introduction}

In recent years, due to different geothermal gradients, it has been noticed that the heating rate is one of the significant factors that affect the mechanical properties of a rock mass in deep underground rock engineering such as deep sea and underground tunnels, nuclear waste disposal, and deep mining. It is also important in the study on rock engineering fire. Meanwhile, impact loads including blasting excavation and earthquakes are not rare and can even be common. Hence, studying the effect of the heating rate on the dynamic mechanical properties of rocks is very worthwhile and necessary. The main purpose of this study is to offer a strong theoretical foundation and guidance to ensure the safety of rock engineering.

Importantly, more and more mines around the world are being deeply exploited due to a sharp rise in demand for basic resources because of the rapid social development and exhausted shallow resources in recent years. For example, at the Zhangxiaolou mine and Dongguashan copper mine in China, the exploitation depths are about 1100 and $1000 \mathrm{~m}$, respectively, while the exploitation depth of the AngloGold mine in South Africa has already reached around $3700 \mathrm{~m}$. Because of resource exhaustion, the depth of rock engineering such as mining will increase continuously in the future. Deep rock masses simultaneously suffer from various complex and dangerous environments including high ground stress, high humidity, high temperature caused by high-heat injection, and strong dynamic disturbance generated by drilling or blasting $[1-3]$. This situation is very different from that of shallow rock masses. Among those complex environments, temperature is one of the significant factors that affect rock engineering, and temperature mainly changes the mechanical properties due to the varying physical properties including the density, longitudinal wave velocity, permeability, and porosity [4-8]. The value of stress in the rock mass 
decreases by about $0.5 \mathrm{MPa}$ when the temperature increases by $1^{\circ} \mathrm{C}$. So far, the maximum underground temperature has reached about $100^{\circ} \mathrm{C}$; for instance, the maximum ground temperature at a deep coal mine in China is close to $50^{\circ} \mathrm{C}$ and the ground temperature increases to $70^{\circ} \mathrm{C}$ at a depth of $3 \mathrm{~km}$ below the ground level in a gold mine in India. Since it was recognized that temperature is an important factor that affects rock engineering, numerous researchers have devoted themselves to investigating the thermal effect on rock physical and mechanical characteristics including static and dynamic mechanical properties [9-11]. For example, Yin et al. [12] pointed out that the dynamic tensile strength of rock was enhanced before $100^{\circ} \mathrm{C}$, but its value declined rapidly when the temperature was higher than $100^{\circ} \mathrm{C}$. In another paper, Yin et al. [13] carried out an impact loading experiment on granite subjected to temperature and axial pressure at temperatures rising from room temperature to $300^{\circ} \mathrm{C}$ by using a split Hopkinson pressure bar (SHPB) with a heating device and discovered that both the compressive strength and the longitudinal wave velocity decreased with the increasing temperature, while the damage increased with rising temperature. By carrying out both static and dynamic experiments on thermally treated biotite granite, Liu and $\mathrm{Xu}$ [14] discovered that the dynamic compressive strength of thermally treated biotite granite improved to varying degrees compared with the static compressive strength. Before $600^{\circ} \mathrm{C}$, the overall change in the dynamic compressive strength of biotite granite was not obvious, but after $600^{\circ} \mathrm{C}$, the dynamic compressive strength decreased significantly. What is more, temperature also plays a significant role in many other engineering practices besides deep mining [15-17], such as in the disposal of highly radioactive nuclear waste, the underground storage of petroleum and natural gas, the postdisaster reconstruction of underground rock engineering [18], and the development and utilization of geothermal resources. A recent research predicted that the maximum temperature of confining rock could reach $300^{\circ} \mathrm{C}$ owing to the decay of radioactive element during the disposal of highly radioactive nuclear waste [19].

In addition, the macroscopic mechanical properties of rock differ from others because of the different heating rates and heat injection in the ore bed when it comes to deep mining. When the exploitation depth increases, the temperature increases with different geothermal gradients varying from 30 to $50^{\circ} \mathrm{C} / \mathrm{km}$ due to the different hydrogeology and existing conditions, which can finally change the value of the stress in the rock mass. The geothermal gradient can be very high, even reaching about $100^{\circ} \mathrm{C} / \mathrm{km}$ in some specific places. From the point of view of temperature, Thirumalai and Demou [20] discovered that the thermal expansion increased gradually as the heating rate increased by testing granite samples, which were heat treated at rates of 5,20 , and $50^{\circ} \mathrm{C} / \mathrm{min}$ to temperatures ranging from 20 to $400^{\circ} \mathrm{C}$. By carrying out an experiment on gabbro heated to $300^{\circ} \mathrm{C}$ with heating rates of 1 and $5^{\circ} \mathrm{C} / \mathrm{min}$, Richter and Simmons [21] showed the same phenomenon, which was, the higher the heating rate, the larger the expansion coefficient; they stated that the thermal cracking was more significant under the higher heating rate. Yong and Wang [22] showed by experimental study that the heating rate was one of the important factors affecting the rock properties. Furthermore, Li et al. [23] pointed out that the natural and mechanical properties of sandstone gradually decreased with an increasing heating rate. Due to different geothermal gradients and the different distances to the heat source including highly radioactive nuclear waste and fire, the heating rate could be different. Hence, the heating rate is also a factor that should be considered in rock engineering.

However, despite the abovementioned researches, the effect of the heating rate on the rock dynamic mechanical properties has been neglected to a large extent. Only a few studies referred to the effects of the heating rate on the physical $[24,25]$ and mechanical properties of rocks, and they emphasized that the heating rate was the key factor making a large difference in the investigation of the mechanical properties of materials, which can both significantly affect the crystal texture or recombination and influence the macroscopic mechanical properties of rocks. Thus, in order to ensure the safety and efficiency of rock engineering under complex conditions and to determine the effect of the heating rate on the dynamic mechanical characteristics of rocks, in this paper, an impact experiment was carried out at different heating rates $\left(0,2,20\right.$, and $\left.40^{\circ} \mathrm{C} / \mathrm{min}\right)$ and temperatures $\left(400,600\right.$, and $\left.800^{\circ} \mathrm{C}\right)$. Meanwhile, the laws of change and correlations among the dynamic compressive strength, peak strain, dynamic elastic modulus, and heating rate were analyzed and discussed. Furthermore, the microscopic characteristics and failure process were observed by scanning electron microscopy (SEM) and high-speed video camera, respectively.

\section{Laboratory Experiment}

2.1. Sample Preparation. Since the objective of the study was to obtain the effect of the heating rate on the dynamic compressive properties of granite, the tested samples were cored from the same rock blocks obtained in Changsha, China, in order to avoid any variation due to natural anisotropy of samples. As is shown in Figure 1(a), the measured average grain size of the granite is around $2.1 \mathrm{~mm}$, and the rock mainly consist of $46.02 \%$ quartz, $16.52 \%$ biotite, $35.15 \%$ K-feldspar, and $2.31 \%$ other components. There were no distinct layering, laminations, or flaws observed in the sample surface, as shown in Figure 1(b). The granite used here was processed into a cylinder with dimensions of $\varphi 50 \mathrm{~mm} \times 25$ $\mathrm{mm}$. Particularly, in order to ensure their parallelism, flatness, and finish, both ends of the samples were polished, controlling the parallelism within $\pm 0.05 \mathrm{~mm}$ and the surface flatness within $\pm 0.02 \mathrm{~mm}$. Furthermore, the longitudinal wave velocity of the polished sample was measured by using a rock and soil engineering quality detector, and then samples of similar longitudinal wave velocities were selected in order to guarantee the reliability of the experiment. The basic properties of granite, including the static compressive strength, density, longitudinal wave velocity, and elastic modulus, are shown in Table 1. 


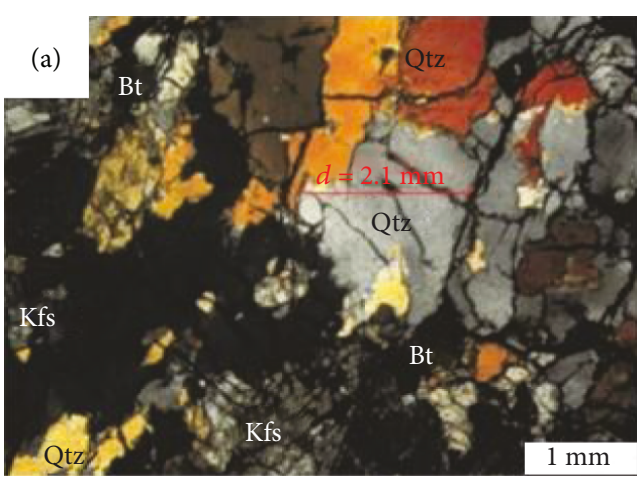

(a)

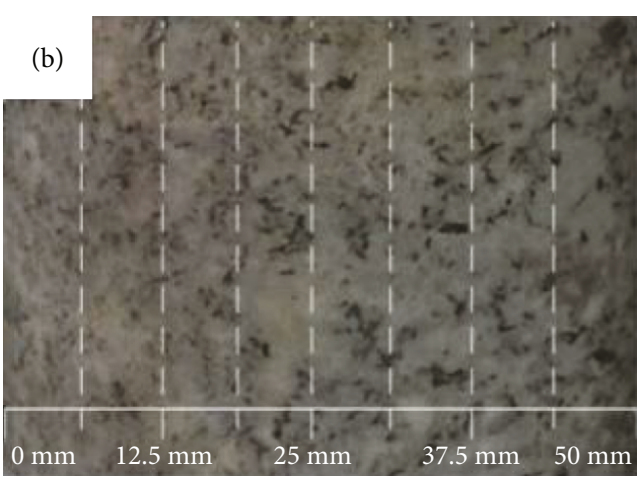

(b)

Figure 1: Petrographic microscopy and the surface images of the granite: (a) petrographic microscopy image of the granite; (b) surface image of the granite. Qtz: quartz; Bt: biotite; Kfs: K-feldspar.

TABLE 1: The basic properties of granite.

\begin{tabular}{lcccc}
\hline Rock type & $\begin{array}{c}\text { Static } \\
\text { compressive } \\
\text { strength } \\
(\mathrm{MPa})\end{array}$ & $\begin{array}{c}\text { Average } \\
\text { density } \\
\left(\mathrm{kg} / \mathrm{m}^{3}\right)\end{array}$ & $\begin{array}{c}\text { Longitudinal } \\
\text { wave velocity } \\
(\mathrm{m} / \mathrm{s})\end{array}$ & $\begin{array}{c}\text { Elastic } \\
\text { modulus } \\
(\mathrm{GPa})\end{array}$ \\
\hline Granite & 131.25 & 2641.92 & 4450.95 & 29.71 \\
\hline
\end{tabular}

2.2. Experimental Apparatus. The main test apparatus used here are the SHPB, variable-speed heating furnace, and SEM, as shown in Figures 2(a)-2(c), respectively. The rock dynamic compressive experiment is carried out by the SHPB experimental system, which primarily consists of a spindle punch, an emission cavity, a gas gun, an incident bar with dimensions of $\varphi 50 \mathrm{~mm} \times 2000 \mathrm{~mm}$, a transmission bar $\varphi$ $50 \mathrm{~mm} \times 1500 \mathrm{~mm}$, an absorbing bar of $\varphi 50 \mathrm{~mm} \times 500 \mathrm{~mm}$, a signal recording device including a high dynamic strain indicator and oscilloscope, and a data-processing device including computer. The ultimate strength, wave velocity, and density of the bar are $800 \mathrm{MPa}, 5400 \mathrm{~m} / \mathrm{s}$, and $7810 \mathrm{~kg} /$ $\mathrm{m}^{3}$, respectively. The complete stress-strain curve could be obtained due to the higher stiffness of the high-strength alloy bar compared to the rock sample. In addition, a stable strain rate of half the sinusoidal stress wave is produced by a spindle punch. The incident, reflected, and transmitted waves are measured by the signals recorded through strain gauges fixed on the incident and transmission bars. Correspondingly, the stress, $\sigma(t)$, strain, $\varepsilon(t)$, and strain rate, $\varepsilon^{\cdot}(t)$ could be calculated from the cross-sectional area of the sample, $A_{S}$; the cross-sectional area of the pressure bar, $A_{0}$; the wave velocity of the pressure bar, $C_{0}$; the elastic modulus of the bar, $E_{0}$; the length of the rock sample, $L_{S}$; the incident strain, $\varepsilon_{\mathrm{I}}$; the reflected strain, $\varepsilon_{\mathrm{R}}$; and the transmitted strain, $\varepsilon_{\mathrm{T}}$, by using Formulas (1), (2), and (3), respectively. The variable-speed heating furnace, which includes a heating cabinet and smart controller, is designed to have a rated power of $4 \mathrm{~kW}$, a maximum temperature of $1200^{\circ} \mathrm{C}$, and a maximum heating rate of $40^{\circ} \mathrm{C} / \mathrm{min}$. Thus, the furnace could ensure any heating rate from 0 to $40^{\circ} \mathrm{C} / \mathrm{min}$ controlled by the smart controller. A SEM of type EVO-MA10 is used to observe the internal structure of the rock sample, which mainly consists of two parts: the main body and the controller as shown in Figure 2(c).

$$
\begin{aligned}
& \sigma(t)=\frac{A_{0}}{2 A_{\mathrm{s}}} E\left(\varepsilon_{\mathrm{I}}+\varepsilon_{\mathrm{R}}+\varepsilon_{\mathrm{T}}\right), \\
& \varepsilon(t)=\frac{C_{0}}{L_{\mathrm{s}}} \int_{0}^{t}\left(\varepsilon_{\mathrm{I}}-\varepsilon_{\mathrm{R}}-\varepsilon_{\mathrm{T}}\right) d t, \\
& \dot{\varepsilon}(t)=\frac{C_{0}}{L_{\mathrm{s}}}\left(\varepsilon_{\mathrm{I}}-\varepsilon_{\mathrm{R}}-\varepsilon_{\mathrm{T}}\right) .
\end{aligned}
$$

2.3. Experimental Method. The dynamic experiment on the granite after applying different heating rates and temperature treatments is designed as follows. For the sake of the reliability of the test, the temperatures are classified as 400,600, and $800^{\circ} \mathrm{C}$; because the geothermal gradient generally does not exceed $50^{\circ} \mathrm{C} / \mathrm{km}$, the heating rates are set as $0,2,20$, and $40^{\circ} \mathrm{C} / \mathrm{min}$. There are no less than three samples in each group in order to obtain reliable data, and the samples are numbered consecutively. Before and after heating, the basic properties of the sample such as the longitudinal wave velocity and density should be obtained. It is worth emphasizing that in order to guarantee uniform heating of the rock and to avoid thermal shock in the cooling process, the sample should be kept in the heating body for $30 \mathrm{~min}$ after heating to the target temperature and then slowly cooled in the heating body naturally. Then, the dynamic experiment on the granite after the application of treatments at different heating rates and temperatures could be carried out using the SHPB system with the same incident stress, and the failure process and internal structure of the rock could be obtained by the high-speed camera and SEM, respectively. For the SEM experiment, there are two main steps including slice and observation; the dimension of the granite slice is $10 \mathrm{~mm} \times$ $10 \mathrm{~mm} \times 10 \mathrm{~mm}$. In addition, because the strain rate affects mechanical properties, the strain rate should be almost the same [26, 27]. Finally, the dynamic compressive strength, peak strain, dynamic elastic modulus, and microscopic characteristics of the granite after the treatments at different heating rates and temperatures could all be obtained. 
Split Hopkinson pressure bar

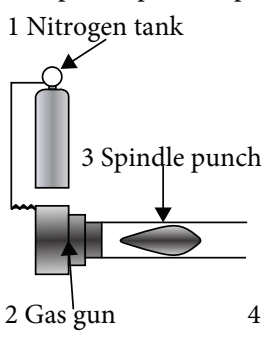

4 Incident bar 5 Strain gauge 6 Rock sample
11 Data-processing device 10 Signal recording device



(a) Split Hopkinson pressure bar

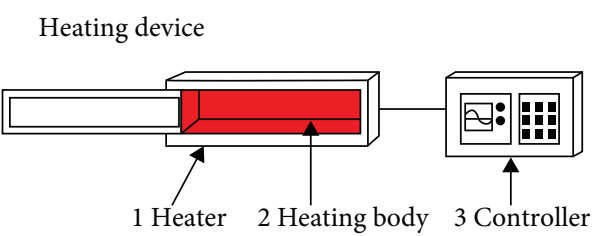

(b) Heating device

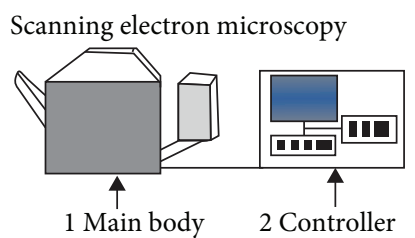

(c) Scanning electron microscopy

FIGURE 2: The main apparatus: (a) split Hopkinson pressure bar (SHPB); (b) variable-speed heating furnace; (c) scanning electron microscopy (SEM).

\section{Dynamic Equilibrium}

To ensure that the experiment is carried out under the condition of one-dimensional stress, the pressure bars, including the incident and transmission bars, should be adjusted to a linear state, and the stresses in the incident and transmission bars should be equal to one another, as shown in Figure 3. Figure 4 shows that the dynamic stress on the transmission bar, which was the sum of the incident and reflected stresses, was absolutely equal to the dynamic stress transmitted on the other side; that is, the dynamic stresses on each side of the sample were balanced.

\section{Experimental Results}

The dynamic mechanical properties of the granite after treatments at different heating rates and temperatures were obtained after removing the large scattered values, as shown in Table 2. The dynamic compressive strength is no more than $186 \mathrm{MPa}$ and clearly decreases with rising heating rate and temperature. That is to say, the effect of the heating rate on the dynamic mechanical properties of granite is also obvious to some extent. The rock treated at a temperature of $25^{\circ} \mathrm{C}$ stands for that of untreated; that is, the rock is treated at the heating rate of $0^{\circ} \mathrm{C} / \mathrm{min}$. The strain rates of rock samples at different temperatures and heating rates are around $58.32 \mathrm{~s}^{-1}$. In addition, Av and Fv denote the average value and fitted value in the paper, respectively.

According to the stress-strain curves of samples after treatments at different heating rates and temperatures, as shown in Figure 5, a complete typical stress-strain curve consisting of four stages is obtained, as shown in Figure 6. The four stages are the compression, elastic, crack-propagation, and unloading stages.

An apparent phenomenon occurs when the heating rate increases: the stress-strain curve clearly changes with

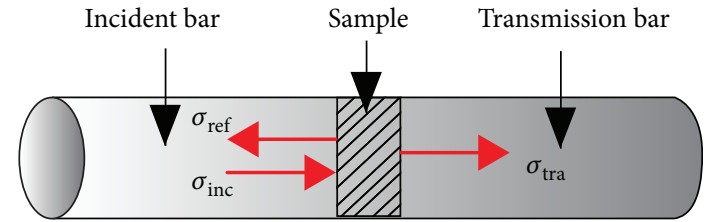

FIgURE 3: Schematic diagram of the stress in pressure bars. $\sigma_{\text {inc }}$ : incident stress; $\sigma_{\text {ref }}$ : reflected stress; $\sigma_{\text {tra }}$ : transmitted stress.

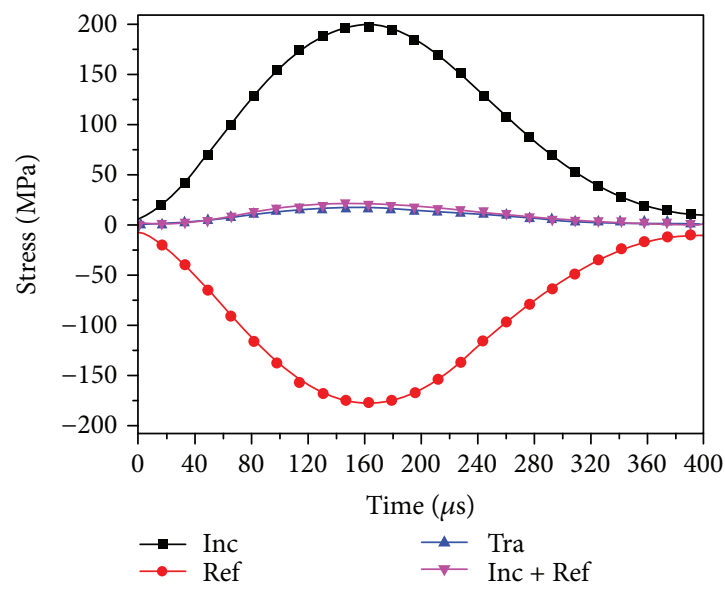

Figure 4: Dynamic stress equilibrium of a typical SHPB test. Inc: incident stress; Ref: reflected stress; Tra: transmitted stress. The ID of the sample is $26 \#$.

variations in the heating rate. In detail, the slope of the curve of the elastic stage and peak value of the curve both decrease gradually as the heating rate increases. Compared to the rock treated at a low heating rate, the compression stage of the samples treated at a higher heating rate is significant and longer because there are more defects, including cracks and 
TABLE 2: Dynamic compressive and physical properties of granite after treatments at different heating rates and temperatures.

\begin{tabular}{|c|c|c|c|c|c|c|c|}
\hline Treated temperature $\left({ }^{\circ} \mathrm{C}\right)$ & $\begin{array}{l}\text { Heating rate } \\
\left({ }^{\circ} \mathrm{C} / \mathrm{min}\right)\end{array}$ & ID & $\begin{array}{c}\text { Dynamic compressive } \\
\text { strength }(\mathrm{MPa})\end{array}$ & $\begin{array}{l}\text { Strain rate } \\
\qquad\left(\mathrm{s}^{-1}\right)\end{array}$ & $\begin{array}{l}\text { Peak strain } \\
\left(10^{-2}\right)\end{array}$ & $\begin{array}{l}\text { Dynamic elastic } \\
\text { modulus (GPa) }\end{array}$ & $\begin{array}{l}\text { Density } \\
\left(\mathrm{kg} / \mathrm{m}^{3}\right)\end{array}$ \\
\hline & & $1 \#$ & 185.61 & 59.33 & 0.52 & 42.16 & 2644.10 \\
\hline \multirow[t]{6}{*}{25} & 0 & $2 \#$ & 182.15 & 57.45 & 0.53 & 41.48 & 2641.40 \\
\hline & & $3 \#$ & 180.47 & 58.21 & 0.55 & 42.06 & 2640.25 \\
\hline & & $5 \#$ & 156.15 & 56.25 & 0.69 & 27.01 & 2619.41 \\
\hline & 2 & $6 \#$ & 156.54 & 58.69 & 0.61 & 32.07 & 2623.54 \\
\hline & & $8 \#$ & 163.15 & 60.12 & 0.64 & 25.49 & 2623.72 \\
\hline & & 9\# & 138.45 & 57.84 & 0.76 & 22.53 & 2613.53 \\
\hline \multirow[t]{9}{*}{400} & 20 & $10 \#$ & 136.49 & 56.45 & 0.79 & 21.04 & 2610.07 \\
\hline & & $11 \#$ & 139.46 & 59.99 & 0.87 & 20.30 & 2621.72 \\
\hline & & $12 \#$ & 133.96 & 52.23 & 1.17 & 13.71 & 2608.22 \\
\hline & 40 & $13 \#$ & 134.46 & 55.88 & 1.03 & 15.03 & 2611.30 \\
\hline & & $14 \#$ & 143.50 & 61.41 & 0.84 & 19.97 & 2612.46 \\
\hline & & $15 \#$ & 122.77 & 62.75 & 0.86 & 30.21 & 2588.26 \\
\hline & 2 & $16 \#$ & 119.62 & 56.01 & 0.81 & 25.81 & 2579.69 \\
\hline & & $18 \#$ & 119.62 & 55.55 & 0.89 & 28.55 & 2576.17 \\
\hline & & $19 \#$ & 96.24 & 58.02 & 1.38 & 10.08 & 2559.88 \\
\hline \multirow[t]{9}{*}{600} & 20 & $20 \#$ & 92.15 & 55.34 & 1.29 & 9.55 & 2553.07 \\
\hline & & $22 \#$ & 97.59 & 63.45 & 1.43 & 14.41 & 2572.65 \\
\hline & & $23 \#$ & 82.16 & 64.24 & 1.68 & 7.79 & 2577.36 \\
\hline & 40 & $24 \#$ & 80.16 & 57.55 & 1.65 & 8.48 & 2544.70 \\
\hline & & $25 \#$ & 79.57 & 54.22 & 1.59 & 10.09 & 2541.98 \\
\hline & & $26 \#$ & 12.28 & 67.38 & 1.66 & 1.15 & 2329.63 \\
\hline & 2 & $27 \#$ & 11.82 & 55.01 & 1.82 & 0.97 & 2316.82 \\
\hline & & $28 \#$ & 11.24 & 51.23 & 2.04 & 0.82 & 2314.47 \\
\hline & & $29 \#$ & 6.11 & 59.39 & 2.67 & 0.39 & 2300.77 \\
\hline \multirow[t]{5}{*}{800} & 20 & $31 \#$ & 5.45 & 51.25 & 2.72 & 0.36 & 2189.84 \\
\hline & & $32 \#$ & 5.51 & 56.41 & 3.03 & 0.31 & 2265.64 \\
\hline & & $33 \#$ & 3.68 & 64.03 & 4.32 & 0.03 & 2041.93 \\
\hline & 40 & $34 \#$ & 3.49 & 55.55 & 4.20 & 0.13 & 1985.84 \\
\hline & & $35 \#$ & 3.84 & 68.23 & 3.67 & 0.15 & 2088.11 \\
\hline
\end{tabular}

pores in the internal structure of the rock sample. Furthermore, the yielding stage is significant when the heating rate is high, especially at higher temperatures. The curve loading part is longer, and the slope of the unloading stage is smaller compared to that of rock treated at a lower heating rate, particularly when the temperature reaches $800^{\circ} \mathrm{C}$, as seen from Figure 5(d). Greater thermal stress occurs owing to the increasing heating rate, which results in the generation of many more defects, including cracks and pores.

4.1. The Effect of Heating Rate on the Dynamic Compressive Strength. In rock engineering, dynamic mechanical behavior is not rare and is even common; it includes, for example, bursts, percussive drilling, and seismic waves. Meanwhile, the dynamic compressive strength is one of the indexes used to evaluate the stability of rock engineering. Hence, it is essential and significant to obtain the dynamic compressive strengths of rocks after treatment at different heating rates.
The correlation between dynamic compressive strength and heating rate at temperatures varying from 400 to $800^{\circ} \mathrm{C}$ is given in Figure 7.

Seen from Figure 7, the value of the dynamic compressive strength decreases accordingly with the increase of the heating rate due to the increasing number of defects caused by the thermal stress. At $400^{\circ} \mathrm{C}$, when the heating rate rises from 0 to $40^{\circ} \mathrm{C} / \mathrm{min}$, the dynamic compressive strength is reduced from 182.74 to $137.31 \mathrm{MPa}$, representing a decrease of $45.43 \mathrm{MPa}$ and a percentage change of $24.86 \%$. As the temperature continues to increase, reaching $600^{\circ} \mathrm{C}$, the dynamic compressive strength decreases from 182.74 to $80.63 \mathrm{MPa}$ when the heating rate varies from 0 to $40^{\circ} \mathrm{C} / \mathrm{min}$, representing a diminution of $102.11 \mathrm{MPa}$ and a percentage change of 55.88\%. Furthermore, the rock is very fragile after being treated at a high heating rate and temperature, and the dynamic compressive strength is only $3.67 \mathrm{MPa}$ at $800^{\circ} \mathrm{C}$ and a heating rate of $40^{\circ} \mathrm{C} / \mathrm{min}$, representing a percentage change of $97.99 \%$ compared to 


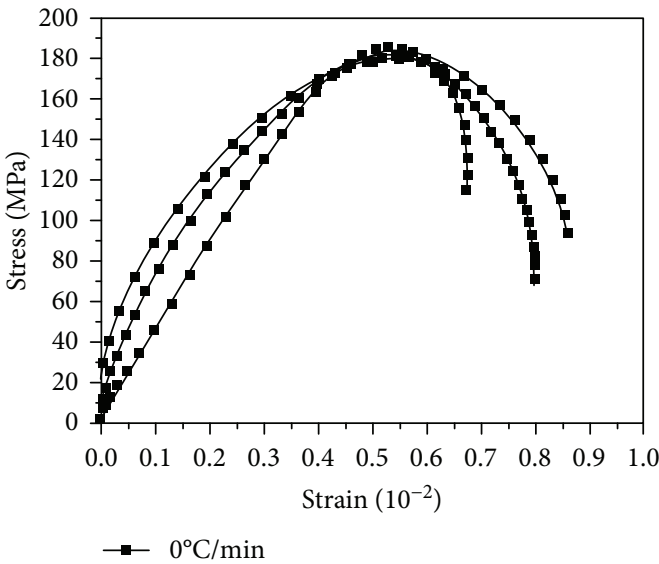

(a)

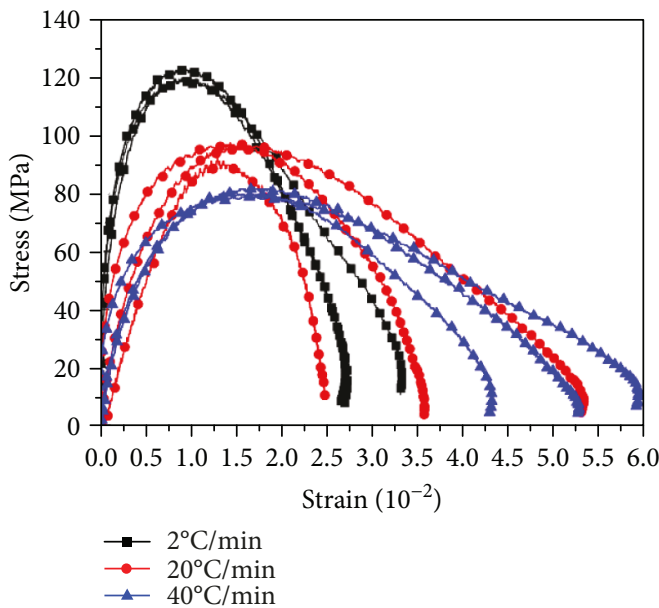

(c)

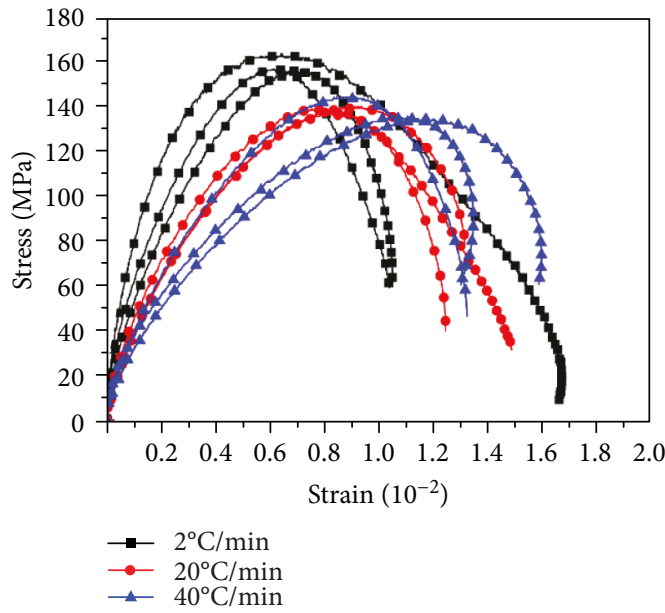

(b)

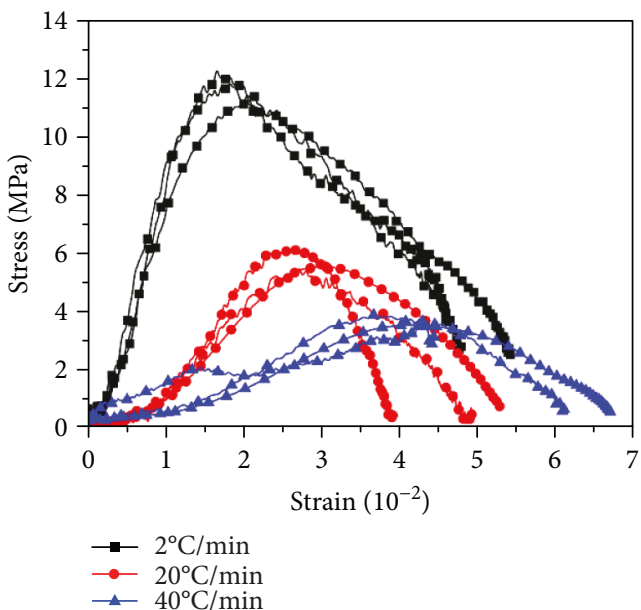

(d)

Figure 5: The stress-strain curves after treatments at different heating rates and temperatures: (a) $25^{\circ} \mathrm{C}$; (b) $400^{\circ} \mathrm{C}$; (c) $600^{\circ} \mathrm{C}$; (d) $800^{\circ} \mathrm{C}$.

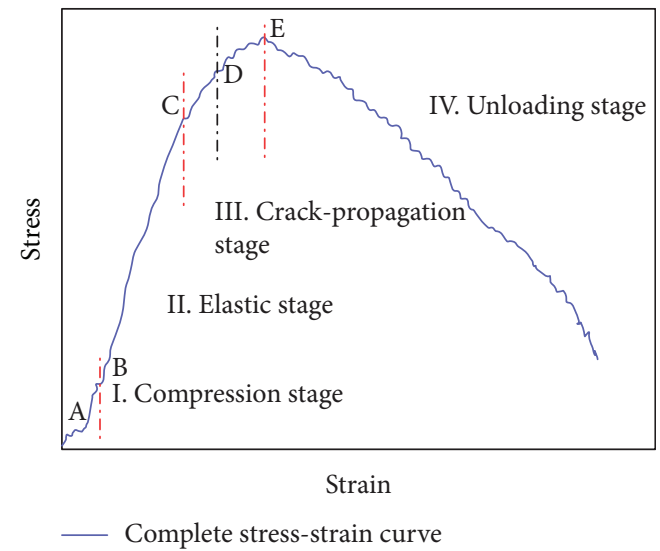

Figure 6: The typical complete stress-strain curve under impact load.

that at $0^{\circ} \mathrm{C} / \mathrm{min}$. The number and size of cracks increase with the rising heating rate and temperature, which lead the dynamic compressive strength to decrease accordingly.
4.2. The Effect of Heating Rate on Peak Strain. On the contrary to the variation of the dynamic compressive strength, the peak strain increases gradually when the heating rate and temperature increase. As can be seen from Figure 8, at $400^{\circ} \mathrm{C}$, the peak strain increases from $0.53 \times 10^{-2}$ to $1.01 \times$ $10^{-2}$ when the heating rate rises from 0 to $40^{\circ} \mathrm{C} / \mathrm{min}$, an increase of $0.48 \times 10^{-2}$.

The peak strain increases from $0.53 \times 10^{-2}$ to $1.01 \times 10^{-2}$ when the heating rate increases from 0 to $40^{\circ} \mathrm{C} / \mathrm{min}$ at a temperature of $600^{\circ} \mathrm{C}$, an addition of $1.11 \times 10^{-2}$. Particularly, when the temperature is $800^{\circ} \mathrm{C}$, the peak strain increases from $0.53 \times 10^{-2}$ to $4.06 \times 10^{-2}$ as the heating rate rises from 0 to $40^{\circ} \mathrm{C} / \mathrm{min}$, representing an increase of $3.53 \times 10^{-2}$. The peak strain increases gradually when the heating rate and temperature increase, which is mainly caused by the enhanced ductility of the rock with the increase of the heating rate and temperature.

4.3. The Effect of Heating Rate on the Dynamic Elastic Modulus. The rock dynamic elastic modulus could describe the elastic deformability of rock under impact load. Here, 




FIGURE 7: The correlation between dynamic compressive strength and heating rate.



FIGURE 8: The correlation between peak strain and heating rate.

the secant modulus which could be calculated by Formula (4) is used to calculate the dynamic elastic modulus, as shown in Figure 9.

$$
E=\frac{\sigma_{50}}{\varepsilon_{50}}=\frac{0.5 \times \sigma_{\mathrm{m}}}{\varepsilon_{50}}
$$

where $E$ is the first type of secant modulus mentioned in the research of Gong et al. [28]; $\sigma_{50}$ is the fifty percent of the dynamic compressive strength, $\sigma_{\mathrm{m}}$; and $\varepsilon_{50}$ is the strain corresponding to $\sigma_{50}$.

As shown in Figure 10, the dynamic elastic modulus decreases with the increase of the heating rate and temperature.

In detail, the dynamic elastic modulus decreases from 41.90 to $16.24 \mathrm{GPa}$ when the heating rate rises from 0 to $40^{\circ} \mathrm{C} / \mathrm{min}$ at the temperature of $400^{\circ} \mathrm{C}$, representing a percentage change of $61.24 \%$. In addition, at $600^{\circ} \mathrm{C}$, the dynamic elastic modulus decreases from 41.90 to $8.79 \mathrm{GPa}$ as the heating rate changes from 0 to $40^{\circ} \mathrm{C} / \mathrm{min}$, representing a percentage change of $79.02 \%$. As the temperature continues to rise, increasing to $800^{\circ} \mathrm{C}$, the dynamic elastic modulus decreases

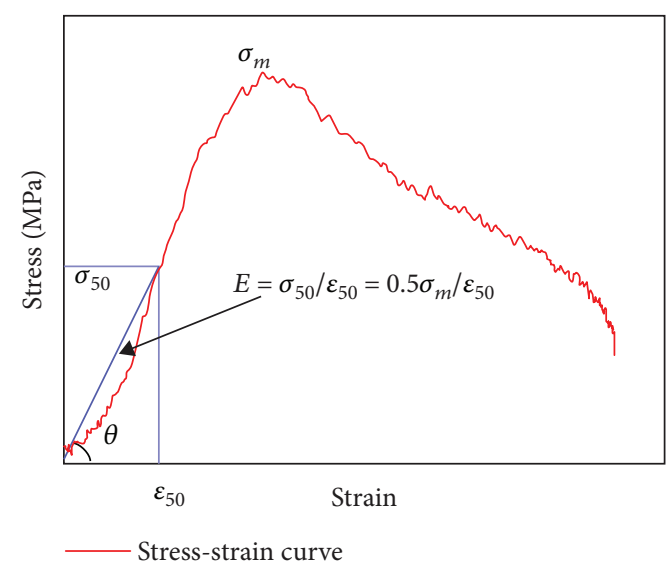

FIgURE 9: Calculation diagram of the dynamic elastic modulus.

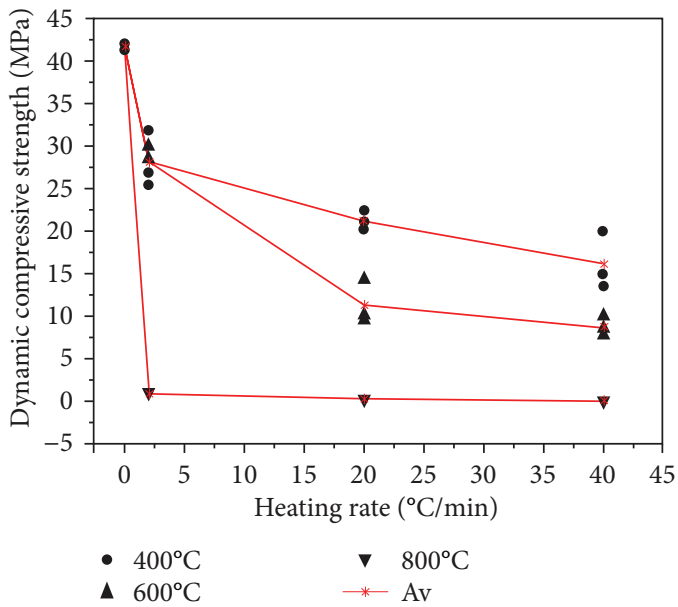

FIgURE 10: The correlation between dynamic elastic modulus and heating rate.

from 41.90 to $0.1 \mathrm{GPa}$, representing a percentage change of around $99.76 \%$. The thermal stress resulting from the increasing heating rate and temperature generates many more defects, including cracks and pores, which finally influences the dynamic elastic modulus.

\section{Analysis and Discussion}

It is not difficult to understand that the output stress is able to change the physical properties, including the internal structure of the material, which finally weakens the mechanical properties; therefore, in this paper, the authors analyzed and discussed the mechanism through which the heating rate affects the mechanical properties from the point of view of essential factors including the thermal stress, internal structure, and crack propagation.

5.1. The Effect Mechanism of the Heating Rate from the Point of View of Thermal Stress. Due to the heterogeneity and anisotropy of the rock, the internal matrix of granite is not entirely compact but has many different original defects such 


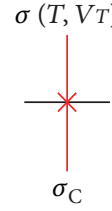
extension of original cracks

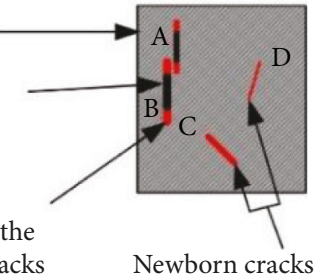

(b)

FIGURE 11: Cracks generated by thermal stress: (a) diagram of stress equilibrium; (b) cracks in the rock sample.

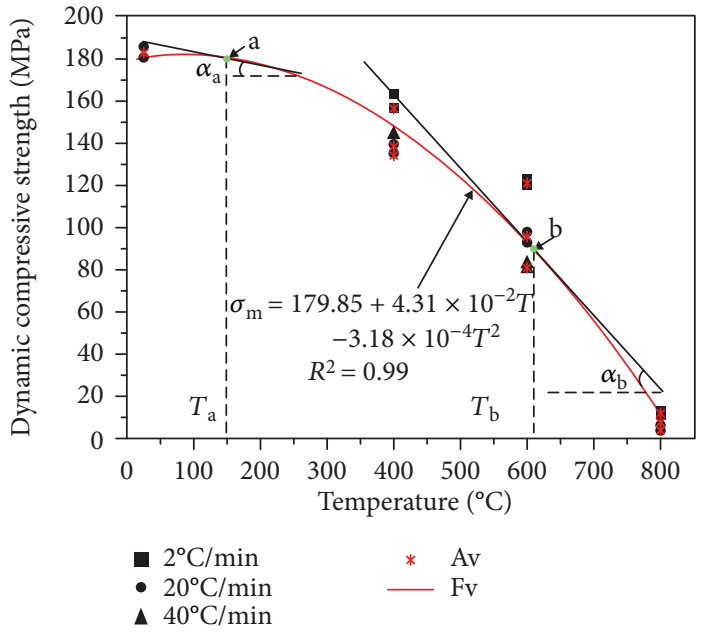

(a)

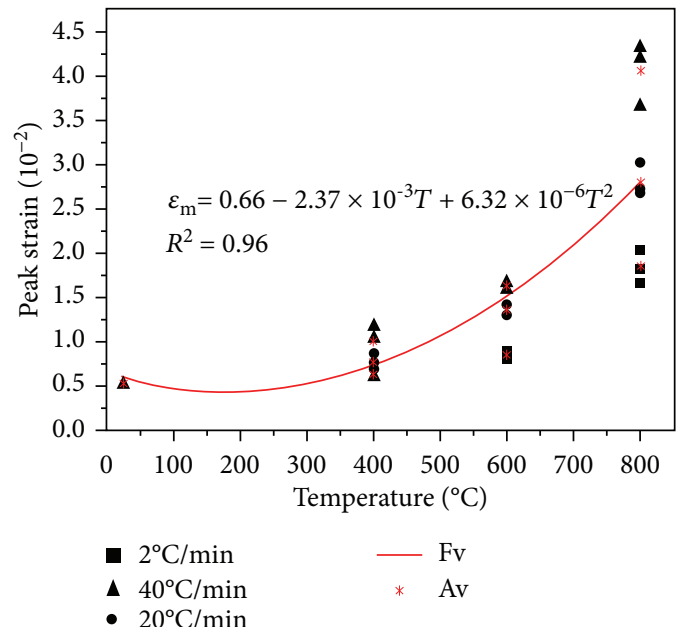

(b)

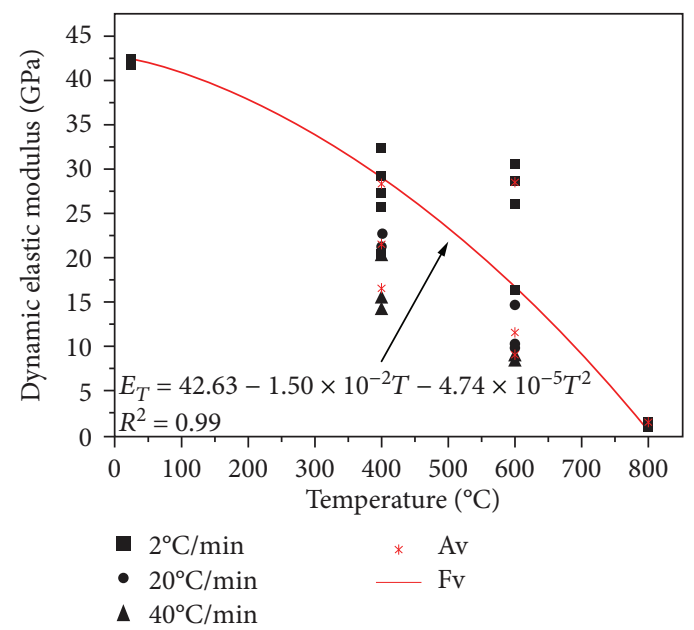

(c)

FIGURE 12: The correlation between dynamic compressive properties and temperature at various heating rates. (a) Correlation between the dynamic compressive strength and temperature at various heating rates; (b) correlation between peak strain and temperature at various heating rates; $(c)$ correlation between the dynamic elastic modulus and temperature at various heating rates.

as cracks. From the point of view of thermal stress, the stresses which cause different original cracks to become extended and generate newborn cracks are not the same. Hence, different thermal stresses correspond to different cracks, including those resulting from the extension of original cracks and newly initiated cracks.
When the thermal stress, $\sigma\left(T, V_{\mathrm{T}}\right)$, conforms to Equation (5), namely, when the thermal stress is equal to the stress which could generate the crack $\sigma_{\mathrm{C}}$, as shown in Figure 11(a), the number and size of the cracks start to increase, which directly influences the dynamic compressive properties of the granite, as seen in Figure 11(b). That is, 


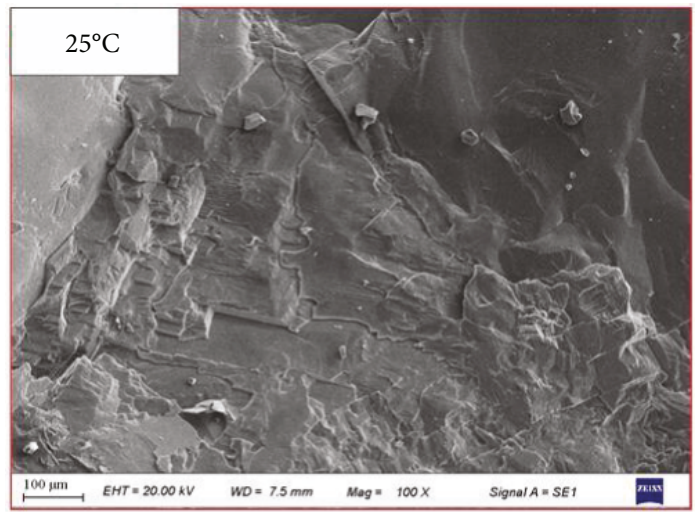

(a)
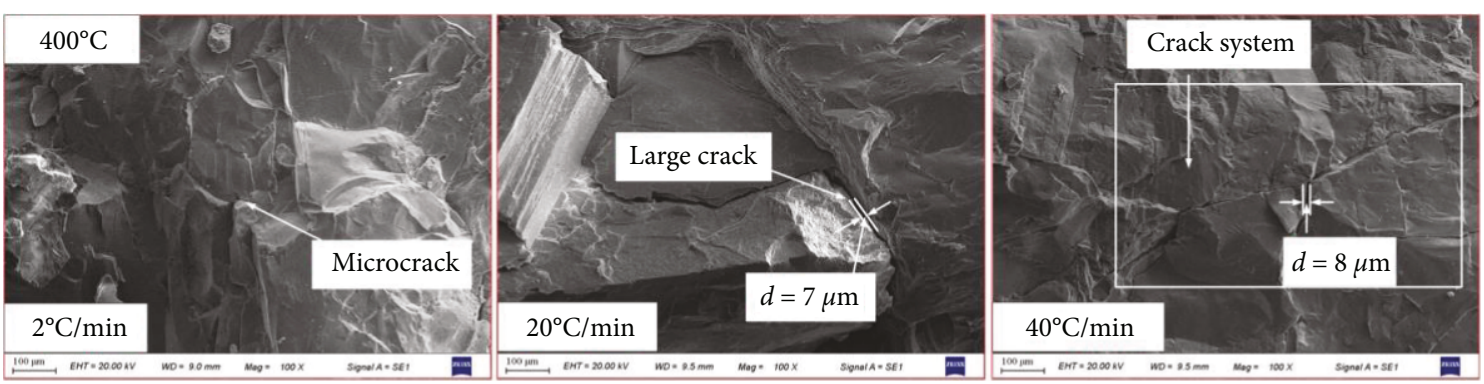

(b)
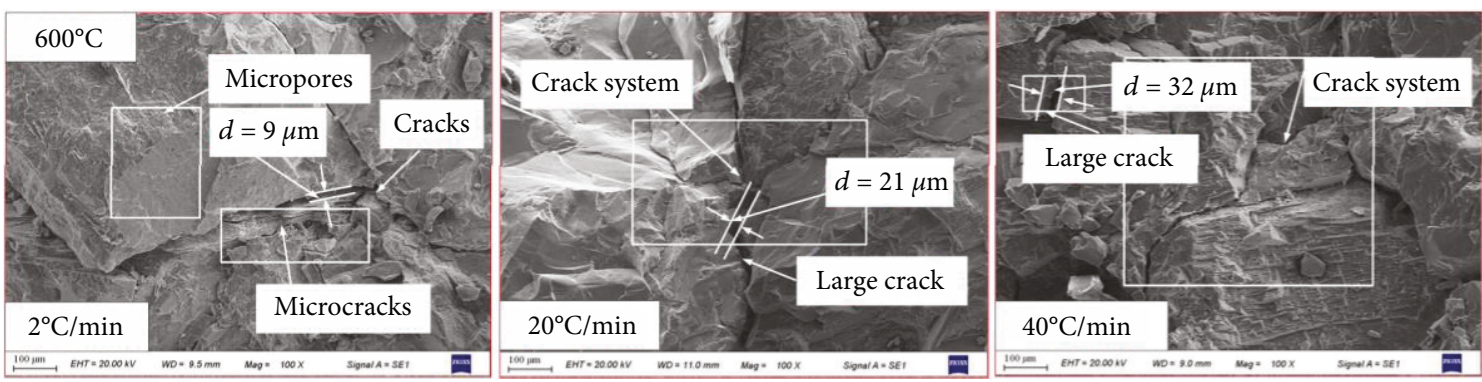

(c)
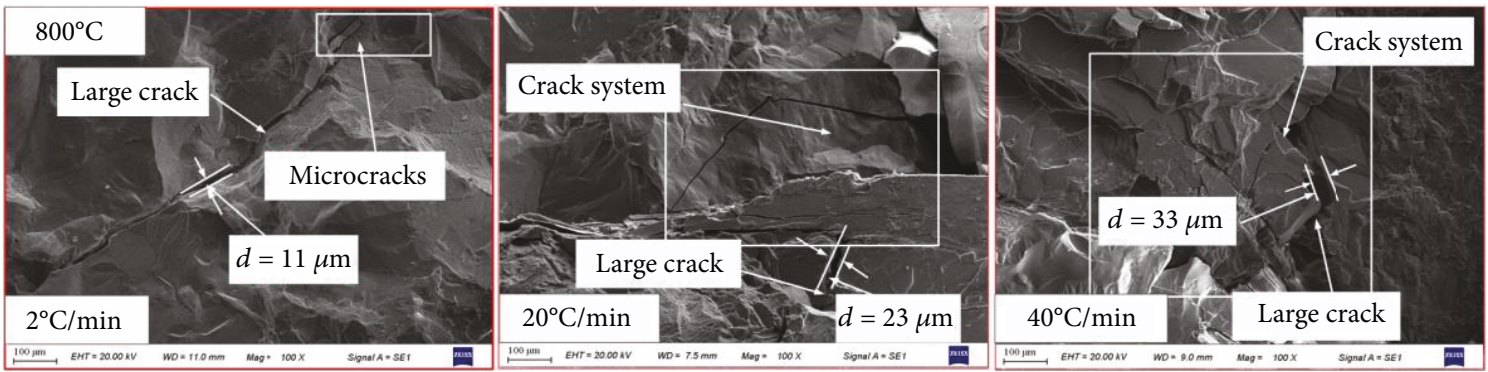

(d)

Figure 13: The microstructure of granite samples after treatments at different heating rates and temperatures: (a) $25^{\circ} \mathrm{C}$; (b) $400^{\circ} \mathrm{C}$; (c) $600^{\circ} \mathrm{C}$; (d) $800^{\circ} \mathrm{C}$.

when the temperature and heating rate increase, the thermal stress increases accordingly. Thus, the number and size of the cracks increase gradually, which directly influence the dynamic compressive properties of the granite.

$$
\sigma\left(T, V_{T}\right)=\sigma_{\mathrm{C}}
$$

When the thermal stress is equal to the stress which could generate a crack, the dynamic compressive strength decreases gradually as the heating rate and temperature increase. As shown in Figure 12(a), the slope of a, $\tan \left(\alpha_{\mathrm{a}}\right)$, is smaller than the slope of $\mathrm{b}, \tan \left(\alpha_{\mathrm{b}}\right)$. The relationship between dynamic compressive strength and temperature at various heating rates could be described by a quadratic function. The peak 
strain and dynamic elastic modulus are subjected to the same phenomenon, as shown in Figures 12(b) and 12(c). The quadratic functions are given as follows:

$$
\begin{aligned}
\sigma_{\mathrm{m}} & =179.85+4.31 \times 10^{-2} \mathrm{~T}-3.18 \times 10^{-4} T^{2}, \\
\varepsilon_{\mathrm{m}} & =0.66-2.37 \times 10^{-3} \mathrm{~T}+6.32 \times 10^{-6} T^{2}, \\
E_{T} & =42.63-1.50 \times 10^{-2} \mathrm{~T}-4.74 \times 10^{-5} T^{2},
\end{aligned}
$$

where $\varepsilon_{\mathrm{m}}$ and $E_{T}$ are peak strain and the dynamic elastic modulus, respectively.

5.2. The Effect Mechanism of the Heating Rate from the Point of View of the Rock Internal Structures. The dynamic compressive properties which influence the safety of rock engineering are related to the microstructures of the rocks. As described in the previous research by Xu et al. [29], the internal structure of rock clearly changes with rising temperature, for example, there is an increase in microcracks and fissures. Considering the effect of heating rate and temperature, in this paper, the authors carried out an SEM experiment to characterize the internal structures of granite samples which were treated at different temperatures of 400 to $800^{\circ} \mathrm{C}$ at a heating rate of 0 to $40^{\circ} \mathrm{C} / \mathrm{min}$ for the purpose of determining the microrelationships among the dynamic compressive properties, temperature, and heating rate. Microstructural diagrams of rock cross-sections which were not affected by the impact loads are shown in Figure 13.

Figure 13 illustrates that the internal structure of the rock is indeed affected by the heating rate and temperature, including cracks. The internal matrix of granite at room temperature $\left(25^{\circ} \mathrm{C}\right)$, namely, at a heating rate of $0^{\circ} \mathrm{C} / \mathrm{min}$, is dense without obvious microcracks; that is, the granite is relatively compact. There are some significant changes in the internal structure of the rock with the increased temperature, mainly consisting in the number and size of cracks, especially when the temperature is high, for example, $600^{\circ} \mathrm{C}$ or higher. In detail, when the temperature is $400^{\circ} \mathrm{C}$, large cracks form in the granite, especially when a crack system that is composed of many interconnected cracks appears gradually at a high heating rate. The same phenomenon occurs in the granite sample treated at the temperature of 600 or $800^{\circ} \mathrm{C}$. The only difference is that the sizes of the cracks are larger when the temperature is high. For example, the width of the largest crack is around $9 \mu \mathrm{m}$ when the temperature is $600^{\circ} \mathrm{C}$ and the heating rate is $2^{\circ} \mathrm{C} / \mathrm{min}$, but when the temperature is $800^{\circ} \mathrm{C}$ and the heating rate is $2^{\circ} \mathrm{C} / \mathrm{min}$, the width of the largest crack increases to about $11 \mu \mathrm{m}$. In addition, the number of cracks also increases with increasing temperature. The effect of the temperature on the internal structure of the rock is one of the important reasons why the dynamic compressive properties are affected.

The number and size of cracks increase with the increasing heating rate. For instance, when the temperature is $800^{\circ} \mathrm{C}$, the width of the largest crack of the granite sample is only around $11 \mu \mathrm{m}$ at the heating rate of $2^{\circ} \mathrm{C} / \mathrm{min}$, whereas it reaches $33 \mu \mathrm{m}$ at $40^{\circ} \mathrm{C} / \mathrm{min}$. In addition, there are many more large cracks when the heating rate is high at $800^{\circ} \mathrm{C}$. In particular, a crack system consisting of many interconnected

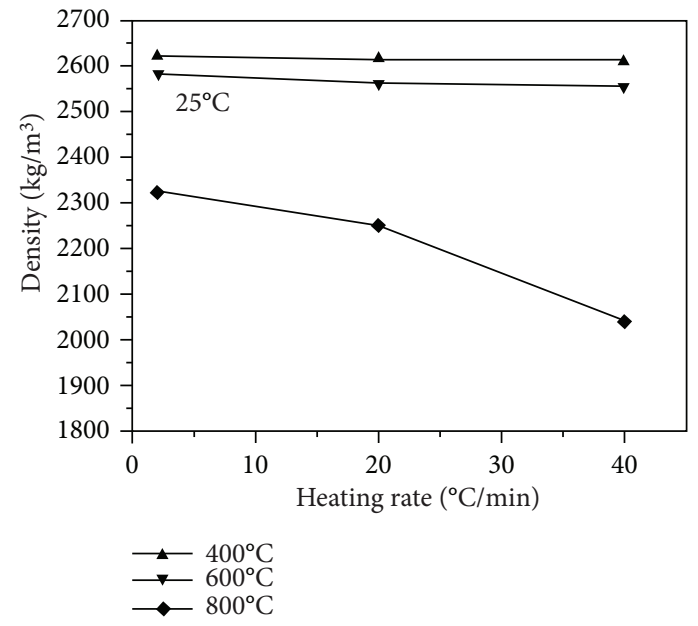

FIgURE 14: The correlation between density and the heating rate.

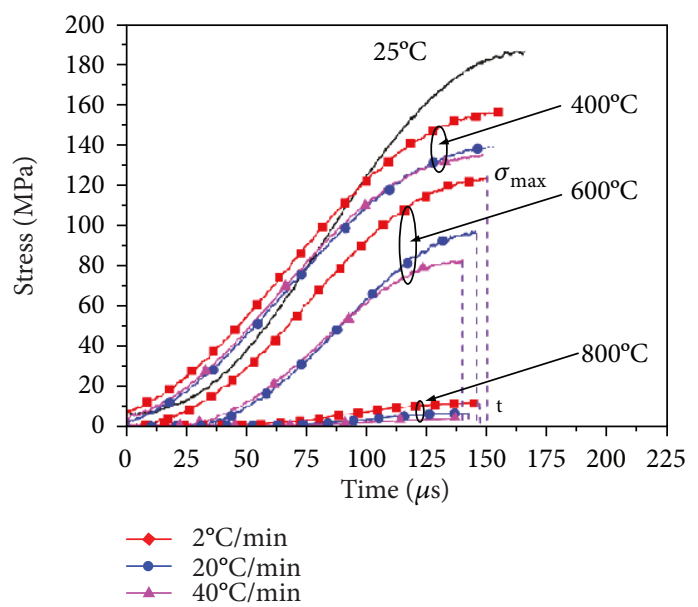

FIgURE 15: The correlation curve between the value of stress before the peak and time (note: $\sigma_{\max }$ is the peak stress in the experimental process).

cracks appears when the heating rate is high. When the temperature is high, the increased thermal stress caused by the rising heating rate weakens the physical properties of the rock, such as the density, as shown in Figure 14, which finally influences the mechanical properties of the granite. Figure 14 shows that the density of the rock decreases gradually with increasing heating rate.

5.3. The Effect Mechanism of the Heating Rate from the Point of View of Crack Propagation. From the point of view of crack propagation in the experimental process under the same impact load, it could be clearly understood that the more cracks the rock contains, the earlier in the experimental process the cracks appear in the surface of the rock. Hence, obtaining the time at which a surface crack appears is one of the effective methods of understanding the effect of the heating rate on the dynamic compressive properties of granite. 


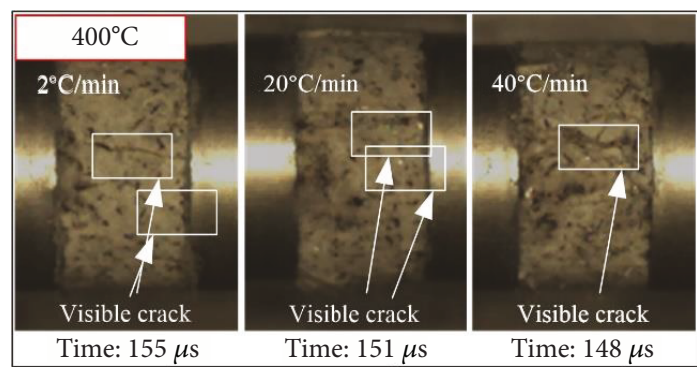

(a)

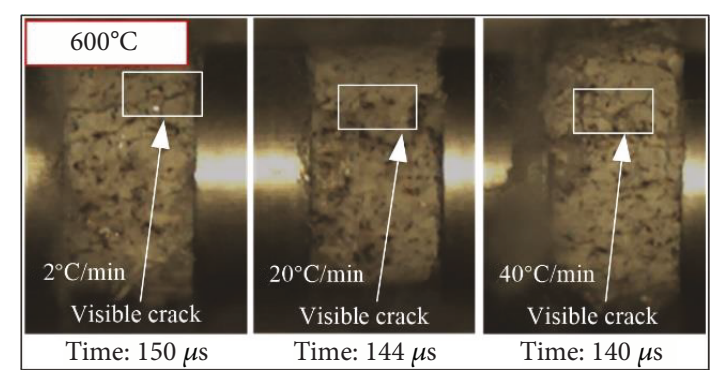

(b)

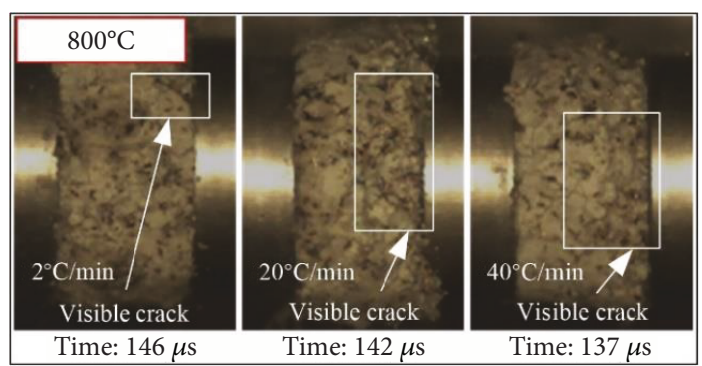

(c)

FIGURE 16: Images obtained by high-speed photography of rocks at various heating rates and temperatures under the impact process: (a) $400^{\circ} \mathrm{C}$; (b) $600^{\circ} \mathrm{C}$; (c) $800^{\circ} \mathrm{C}$.

Figure 15 shows the correlation between the value of stress before the peak stress and time when the value of stress after the peak stress was removed. The higher the heating rate and temperature, the earlier the time when the peak stress is reached, as shown in Figure 15. Highspeed photography photos which describe the visible small cracks were obtained by using the high-speed video camera, as shown in Figure 16.

It is easy to know that the time when visible small cracks appears is almost equal to the time when the peak stress is reached. With regard to the dynamic failure process at $25^{\circ} \mathrm{C}$, visible small cracks appear at around $163 \mu \mathrm{s}$. It could be easily understood that the higher the temperature, the earlier the visible small cracks in the surface of the rock appear. The visible small cracks in the surface of the rock appear earlier as the heating rate increases. For example, when the temperature is $800^{\circ} \mathrm{C}$, the visible small cracks start to appear at 146,142 , and $137 \mu$ s, corresponding to heating rates of 2,20 , and $40^{\circ} \mathrm{C} / \mathrm{min}$. Hence, the higher the heating rate and temperature, the earlier the visible small cracks appear. That is to say, the number and size of defects in the internal structure of the rock increase as the heating rate and temperature increase, which causes the visible small cracks to appear earlier in the experimental process, finally changing the dynamic compressive properties of granite.

\section{Conclusions}

Conclusions regarding the dynamic compressive strength, peak strain, dynamic elastic modulus, and microstructural characteristics were drawn during the investigation and discussion. The main conclusions are given as follows:
(1) The dynamic compressive strength and dynamic elastic modulus obviously decrease with the increasing heating rate, whereas the peak strain increases gradually with the increasing heating rate

(2) Both the heating rate and temperature influence the dynamic compressive properties of granite. The relationship among the dynamic compressive strength, peak strain, dynamic elastic modulus, and temperature at varied heating rates could be described by the quadratic functions

(3) The number and size of the cracks increase with the rising heating rate and temperature. It is worth noticing that the increase of thermal stress with increasing heating rate and temperature leads to increase in the number and size of cracks, which finally causes a change of the dynamic compressive mechanical properties of granite

\section{Data Availability}

No data were used to support this study.

\section{Conflicts of Interest}

The authors declare that they have no conflicts of interest.

\section{Acknowledgments}

The authors wish to acknowledge the research grants from the National Natural Science Foundation of China (No. 51774325), the State Key Program of the National Natural Science Foundation of China (No. 41630642), the State Key Research Development Program of China (No. 
2016YFC0600706), the Innovation-Driven Project of Central South University (No. 2017CX006), the Natural Science Foundation of Hunan Province of China (No. 2017JJ3389), and the Fundamental Research Funds for the Central Universities of Central South University (No. 2018zzts212).

\section{References}

[1] P. Wang, T. B. Yin, X. B. Li, S. Zhang, and L. Bai, "Dynamic properties of thermally treated granite subjected to cyclic impact loading," Rock Mechanics and Rock Engineering, vol. 52, no. 4, pp. 991-1010, 2019.

[2] T. B. Yin, L. Bai, X. B. Li, and S. Zhang, "Effect of thermal treatment on the mode I fracture toughness of granite under dynamic and static coupling load," Engineering Fracture Mechanics, vol. 199, pp. 143-158, 2018.

[3] T. B. Yin, S. S. Zhang, X. B. Li, and L. Bai, "Evolution of dynamic mechanical properties of heated granite subjected to rapid cooling," Geomechanics and Engineering, vol. 16, no. 5, pp. 483-493, 2018.

[4] M. Darot and T. Reuschlé, "Acoustic wave velocity and permeability evolution during pressure cycles on a thermally cracked granite," International Journal of Rock Mechanics and Mining Science, vol. 37, no. 7, pp. 1019-1026, 2000.

[5] A. M. Ferrero and P. Marini, "Experimental studies on the mechanical behaviour of two thermal cracked marbles," Rock Mechanics and Rock Engineering, vol. 34, no. 1, pp. 57-66, 2001.

[6] S. Ghabezloo and J. Sulem, "Stress dependent thermal pressurization of a fluid-saturated rock," Rock Mechanics and Rock Engineering, vol. 42, no. 1, pp. 1-24, 2009.

[7] H. Yavuz, S. Demirdag, and S. Caran, "Thermal effect on the physical properties of carbonate rocks," International Journal of Rock Mechanics and Mining Science, vol. 47, no. 1, pp. 94103, 2010.

[8] L. L. N. Mambou, J. Ndop, and J. M. B. Ndjaka, “Theoretical investigations of mechanical properties of sandstone rock specimen at high temperatures," Journal of Mining Science, vol. 50, no. 1, pp. 69-80, 2014.

[9] V. Brotóns, R. Tomás, and J. C. Alarcón, “Temperature influence on the physical and mechanical properties of a porous rock: San Julian's calcarenite," Engineering Geology, vol. 167, no. 4, pp. 117-127, 2013.

[10] A. Ozguven and Y. Ozcelik, "Effects of high temperature on physico-mechanical properties of Turkish natural building stones," Engineering Geology, vol. 183, pp. 127-136, 2014.

[11] Y. Y. Zhao, Z. J. Feng, B. P. Xi, Z. Wan, D. Yang, and W. Liang, "Deformation and instability failure of borehole at high temperature and high pressure in hot dry rock exploitation," Renewable Energy, vol. 77, pp. 159-165, 2015.

[12] T. B. Yin, X. B. Li, W. Z. Cao, and K. Xia, "Effects of thermal treatment on tensile strength of Laurentian granite using Brazilian test," Rock Mechanics and Rock Engineering, vol. 48, no. 6, pp. 2213-2223, 2015.

[13] T. B. Yin, R. H. Shu, X. B. Li, P. Wang, and L.-J. Dong, "Combined effects of temperature and axial pressure on dynamic mechanical properties of granite," Transactions of Nonferrous Metals Society of China, vol. 26, no. 8, pp. 2209-2219, 2016.

[14] S. Liu and J. Y. Xu, "Mechanical properties of Qinling biotite granite after high temperature treatment," International
Journal of Rock Mechanics and Mining Science, vol. 71, no. 8, pp. 188-193, 2014.

[15] Z. X. Zhang, J. Yu, S. Q. Kou, and P. A. Lindqvist, "Effects of high temperatures on dynamic rock fracture," International Journal of Rock Mechanics and Mining Science, vol. 38, no. 2, pp. 211-225, 2001.

[16] M. G. Alishaev, I. M. Abdulagatov, and Z. Z. Abdulagatova, "Effective thermal conductivity of fluid-saturated rocks: experiment and modeling," Engineering Geology, vol. 135-136, no. 7, pp. 24-39, 2012.

[17] B. Vaferi, V. Gitifar, P. Darvishi, and D. Mowla, "Modeling and analysis of effective thermal conductivity of sandstone at high pressure and temperature using optimal artificial neural networks," Journal of Petroleum Science and Engineering, vol. 119, no. 5, pp. 69-78, 2014.

[18] M. J. Heap, P. Baud, and P. G. Meredith, "Brittle creep in basalt and its application to time-dependent volcano deformation," Earth and Planetary Science Letters, vol. 307, no. 1-2, pp. 7182, 2011.

[19] J. A. Hudson, O. Stephansson, and J. Andersson, "Coupled T$\mathrm{H}-\mathrm{M}$ issues relating to radioactive waste repository design and performance," International Journal of Rock Mechanics and Mining Science, vol. 38, no. 1, pp. 143-161, 2001.

[20] K. Thirumalai and S. G. Demou, "Effect of reduced pressure on thermal-expansion behavior of rocks and its significance to thermal fragmentation," Journal of Applied Physics, vol. 41, no. 13 , pp. 5147-5151, 1970.

[21] D. Richter and G. Simmons, "Thermal expansion behavior of igneous rocks," International Journal of Rock Mechanics and Mining Science \& Geomechanics Abstracts, vol. 11, no. 10, pp. 403-411, 1974.

[22] C. Yong and C. Wang, "Thermally induced acoustic emission in Westerly granite," Geophysical Research Letters, vol. 7, no. 12, pp. 1089-1092, 1980.

[23] M. Li, X. Mao, L. Cao, H. Pu, and A. Lu, "Influence of heating rate on the dynamic mechanical performance of coal measure rocks," International Journal of Geomechanics, vol. 17, no. 8, article 04017020, 2017.

[24] M. V. Kök, "Heating rate effect on the DSC kinetics of oil shales," Journal of Thermal Analysis and Calorimetry, vol. 90, no. 3, pp. 817-821, 2007.

[25] D. Wu, G. J. Liu, S. C. Chen, and R. Sun, “An experimental investigation on heating rate effect in the thermal behavior of perhydrous bituminous coal during pyrolysis," Journal of Thermal Analysis and Calorimetry, vol. 119, no. 3, pp. 2195-2203, 2015.

[26] S. Liu and J. Y. Xu, "Effect of strain rate on the dynamic compressive mechanical behaviors of rock material subjected to high temperatures," Mechanics of Materials, vol. 82, pp. 28 38, 2015.

[27] T. B. Yin, S. S. Zhang, X. B. Li, and L. Bai, "A numerical estimate method of dynamic fracture initiation toughness of rock under high temperature," Engineering Fracture Mechanics, vol. 204, pp. 87-102, 2018.

[28] F. Q. Gong, X. B. Li, and X. L. Liu, "Preliminary experimental study of characteristics of rock subjected to 3D coupled static and dynamic loads," Chinese Journal of Rock Mechanics and Engineering, vol. 30, no. 6, pp. 1178-1190, 2011.

[29] X. L. Xu, F. Gao, X. M. Shen, and H.-P. Xie, "Mechanical characteristics and microcosmic mechanisms of granite under temperature loads," Journal of China University of Mining and Technology, vol. 18, no. 3, pp. 413-417, 2008. 

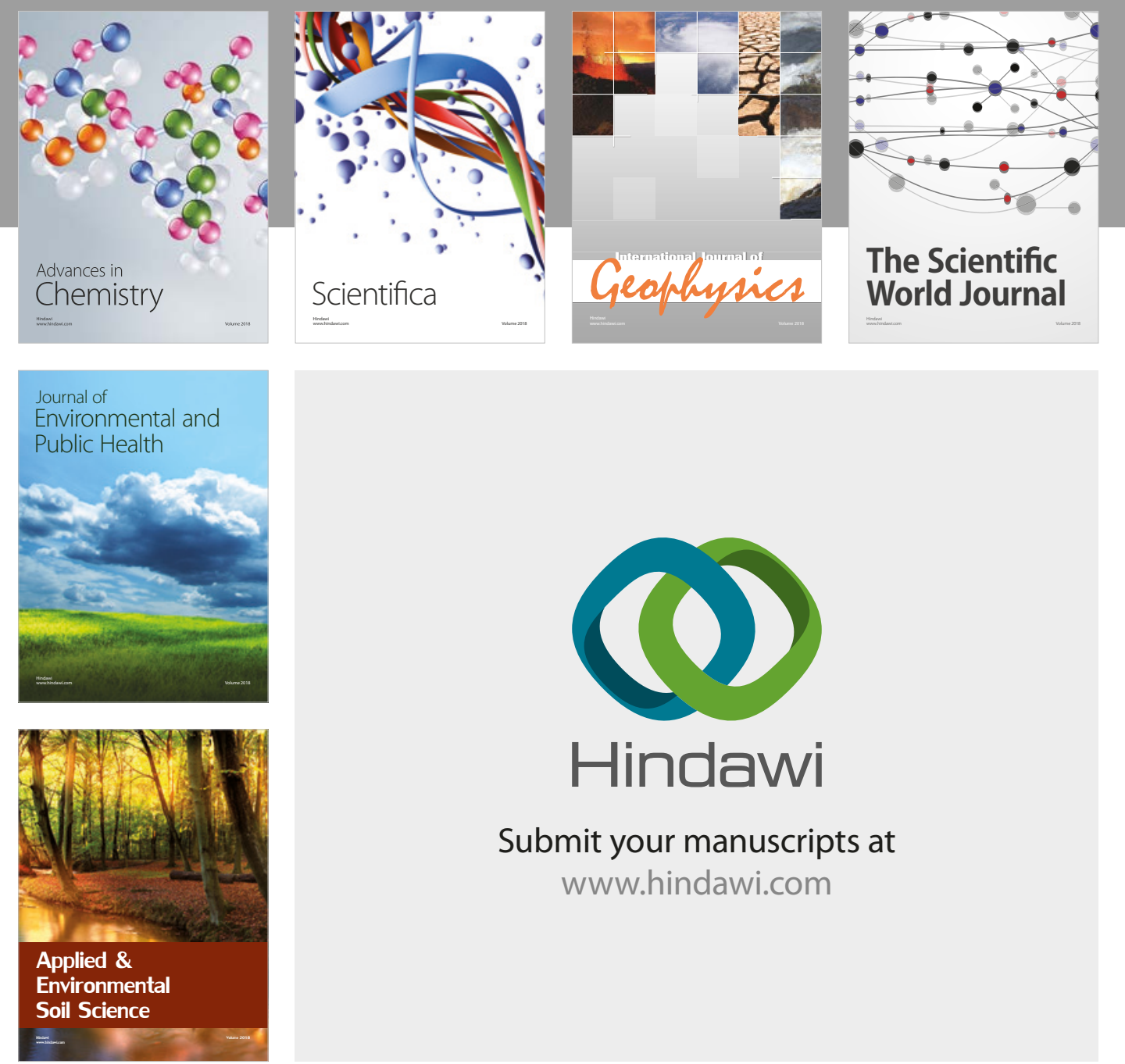

The Scientific

\section{World Journal}
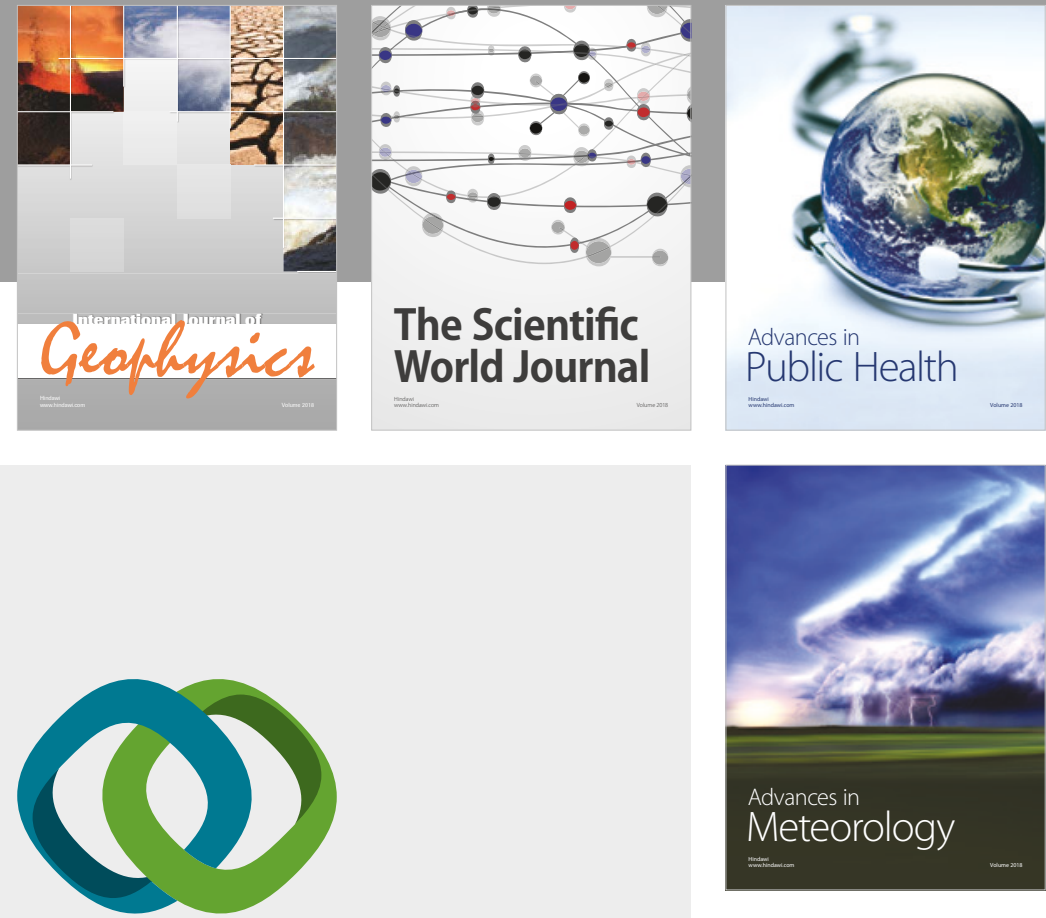

Advan

Public Health

\section{Hindawi}

Submit your manuscripts at

www.hindawi.com
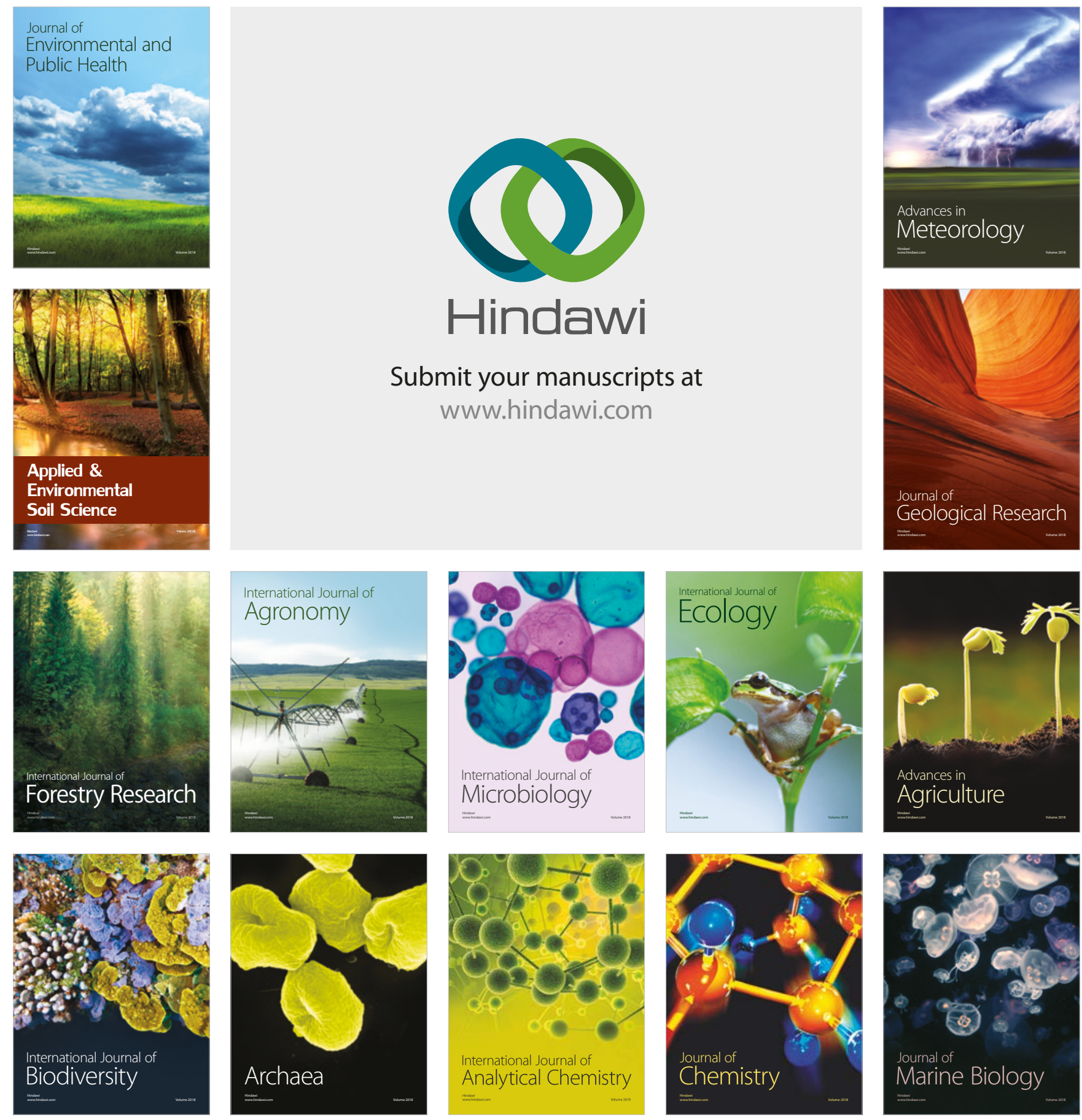